\title{
Ciclos de Entendimento de Conceitos Associados ao Desenho de Experimentos Exibidos ao Realizar uma APM
}

\section{Ciclos de Entendimiento Asociados al Diseño de Experimentos Exhibidos al Realizar una APM}

\author{
Claudia Orozco-Rodríguez * \\ ORCID iD 0000-0002-7248-7810 \\ Verónica Vargas-Alejo ${ }^{* *}$ \\ ORCID iD 0000-0002-7431-0568
}

\begin{abstract}
Resumo
O objetivo deste artigo é descrever e analisar ciclos progressivos de entendimento que um grupo de alunos universitários exibiram ao realizar uma Atividade Provocadora de Modelos [APM], durante a disciplina Desenho de Experimentos [DE]. O marco teórico foi a Perspectiva de Modelos e Modelação. Houve o interesse de conhecer quais conceitos e procedimentos conformavam cada um dos modelos que os estudantes construíram, com relação ao desenho de experimentos e provas de hipóteses, ao realizar uma APM, no início do curso? Durante a primeira implementação da APM emergiram ideias iniciais de conceitos como: experimento, fator estudado, processo, coleta de dados, variáveis dependentes e independentes, níveis, réplica, tratamentos etc. A segunda pergunta de investigação foi: como se desenvolvem os ciclos progressivos de entendimento referentes aos conceitos de desenhos de experimentos e provas de hipóteses? Para responder isto, foi realizada uma análise qualitativa com enfoque fenomenológico; os resultados mostraram como os sistemas conceituais foram se modificando, ampliando e refinando, a partir de três ciclos iterativos e interativos de entendimento: o ciclo qualitativo, no qual os estudantes usaram variáveis de caráter qualitativo e se expressaram mediante linguagem falada, metáforas e desenhos; o ciclo quantitativo, no qual as variáveis foram descritas mediante informação numérica e expressadas por meio da linguagem falada que fazia referência a operações matemáticas; o ciclo de refinamento, no qual os alunos exibiram os ciclos qualitativos e quantitativos, mas se expressaram usando números, tabelas, gráficos, equações e linguagem falada.
\end{abstract}

Palavras-chave: APM. Ciclo qualitativo. Ciclo quantitativo. Ciclo de refinamento. Ideias iniciais.

\section{Resumen}

El objetivo de este artículo es describir y analizar los ciclos progresivos de entendimiento que un grupo de alumnos universitarios exhibió al realizar una Actividad Provocadora de Modelos [APM], durante una asignatura de Diseño de Experimentos [DE]. El marco teórico fue la Perspectiva de Modelos y Modelación. Interesaba conocer ¿cuáles conceptos y procedimientos conformaban cada uno de los modelos que construyeron los estudiantes, respecto al diseño de experimentos y pruebas de hipótesis, al realizar la APM, al comenzar el curso DE? Durante la primera implementación de la APM emergieron ideas iniciales de conceptos como: experimento, factor estudiado, proceso, recolección de datos, variables dependientes e independientes, niveles, réplica, tratamientos etc. La segunda pregunta de investigación fue: ¿cómo se desarrollaron los ciclos progresivos de entendimiento respecto a los

\footnotetext{
* Doutorado na Formação da Sociedade do Conhecimento, Universidade de Salamanca (USAL). ProfessoraPesquisadora da Universidade de Guadalajara (UdeG), Guadalajara, Jalisco, México. E-mail: claudia.orozcor@academicos.udg.mx.

** Doutorado em Ciências da Educação Matemática, Centro de Investigación y de Estudios Avanzados del Instituto Politécnico Nacional (CINVESTAV-IPN). Professora-Pesquisadora da Universidade de Guadalajara (UdeG), Guadalajara, Jalisco, México. E-mail: veronica.vargas@academicos.udg.mx.
} 
conceptos de diseños de experimentos y pruebas de hipótesis? Para responder esto, se realizó un análisis cualitativo con enfoque fenomenológico; los resultados muestran cómo los sistemas conceptuales se fueron modificando, ampliando y refinando, a partir de tres ciclos iterativos e interactivos de entendimiento: el ciclo cualitativo en el que los estudiantes usan variables de carácter cualitativo y se expresan mediante lenguaje hablado, metáforas y dibujos; el ciclo cuantitativo en el que las variables son descritas mediante información numérica y son expresadas por medio del lenguaje hablado que hace referencia a operaciones matemáticas; y el ciclo de refinamiento, en el que los alumnos exhibieron los ciclos cualitativos y cuantitativos, pero se expresaron utilizando tablas, números, gráficas, ecuaciones y lenguaje hablado.

Palabras clave: APM. Ciclo cualitativo. Ciclo cuantitativo. Ciclo de refinamiento. Ideas iniciales.

\section{Introdução}

A investigação em educação matemática cada vez conta com mais estudos na área da estatística, que centram sua atenção no desenvolvimento da capacidade para interpretar, compreender, avaliar e comunicar informação estatística proveniente de diversos contextos (AYMERICH; GORGORIÓ; ALBARRACÍN, 2017). Lesh e Doerr (2003) propõem desenhos inovadores de atividades, baseados em marcos teóricos, como é o caso da Perspectiva de Modelos e Modelação [PMM], para explicar a aprendizagem da matemática.

Lesh e Harel (2003) mencionam que os modelos são sistemas conceituais utilizados para construir, descrever ou explicar outros sistemas que se expressam mediante sistemas representacionais; estes encontram-se situados na mente do estudante e em meios representacionais: verbal, gráfico, tabular, numérico, figural etc. O processo de modelação matemática é realizado quando se criam estruturas ou sistemas internos mediante ciclos de interação e iteração, que cada vez são mais refinados.

Para chegar a um modelo refinado, é necessário retroalimentação, aplicabilidade e efetividade na solução de alguma situação-problema. Os modelos criados permitem entender a realidade e podem ser transferíveis a diferentes situações (AYMERICH; GORGORIÓ; ALBARRACÍN, 2017). No entanto, aprender a construir modelos não é simples. Vargas-Alejo, Reyes-Rodríguez, Cristóbal-Escalante (2018) mencionam que os indivíduos tendem a generalizar a partir de pouca informação, o que promove que nem sempre se tomem decisões adequadas, fato que resulta crítico na aplicação estatística.

Alguns estudantes têm raciocínios inadequados sobre a probabilidade e a estatística, por exemplo, a inexistência da variabilidade, o conceito de independência entre variáveis, e a confiança, sem fundamentos, de fazer inferências com base em mostras pequenas (SÁNCHEZ, 2017). Apesar de que a probabilidade e a estatística são essenciais para promover a reflexão, geralmente são ensinadas sem contexto, de maneira mecânica e excessivamente formal (BATANERO, 2001). Alguns professores reduzem a aprendizagem da estatística a realizar 
cálculos para resolver exercícios. Se esquecem que um elemento essencial da estatística é seu poder para interpretar, descrever, predizer e controlar fenómenos. Isto tem como consequência que os conceitos sejam aprendidos de forma isolada e sem um significado para o estudante.

Gal (2002 apud AYMERICH; GORGORIÓ; ALBARRACÍN, 2017), aponta que a cultura estatística tem duas características importantes: a capacidade dos indivíduos para interpretar e avaliar certa informação para resolver alguma situação-problema, e suas habilidades para expressão e comunicação, resultantes da compreensão do significado da informação. Por outra parte, a estatística inferencial tem um papel fundamental na matemática aplicada às ciências, no entanto, esses estudos são escassos (RODRÍGUEZ-MUÑIZ; DIAZ, 2018).

Com base no anterior, Aymerich, Gorgorió e Albarracín (2017) mencionam que o uso de atividades relacionadas com a vida real na sala de aula poderia ser útil para modelar situações-problemas mediante estatística. Dessa maneira, o presente artigo tem o objetivo de descrever e analisar os ciclos de entendimento que um grupo de alunos exibiu ao realizar uma APM (LESH; DOERR, 2003) durante uma disciplina DE.

A análise realizada fez-se com base na definição do modelo oferecida por Lesh e Doerr (2003). As seguintes perguntas de investigação foram propostas: 1) Quais conceitos e procedimentos conformavam cada um dos modelos que os estudantes construíram, com relação ao desenho de experimentos e provas de hipóteses, ao realizar a atividade provocadora de modelos no início da disciplina DE? 2) Como se desenvolveram os ciclos progressivos de entendimento relacionado aos conceitos de desenho de experimentos e provas de hipóteses? Isto com o propósito de identificar a evolução da aprendizagem dos estudantes durante a disciplina DE, com base na modificação, extensão e refinamento dos modelos exibidos.

\section{Marco teórico e antecedentes}

Alguns autores realizaram estudos baseados nessa perspectiva, por exemplo, ZapataCardona (2018) aborda a criação de modelos estatísticos para introduzir a análise exploratória mediante uma APM, na qual solicitou, a um grupo de estudantes, a modelação do crescimento da obesidade nos jovens de seu país. Os resultados sugeriram que foram criados modelos abstratos que puderam explicar a realidade. Durante a atividade, emergiram algumas ideias iniciais sobre o raciocínio inferencial informal.

Dvir e Ben-Zvi (2018) implementaram uma sequência didática em alunos da sexta série do ensino fundamental, que não tinham conhecimentos formais de estatística. A proposta foi 
desenhada para incluir múltiplas iterações de análise de dados exploratórios, inferência estatística informal e tarefas de modelação. Os resultados mostraram que a possível progressão da modelação estatística implica três processos por separado, ainda que não independentes: modelação de uma conjetura; modelação dos dados; e um modelo de comparação entre ambos, ressaltando seu papel como potenciador para o desenvolvimento dos processos de modelação.

Doerr, Delmas e Makar (2017) desenharam uma sequência didática para provocar modelos generalizados para extrair inferências baseadas em dois conjuntos de dados. Foi solicitado aos estudantes que realizassem a predição do tempo de voo de um helicóptero de papel, mediante uma APM. Em um primeiro momento, a maioria dos estudantes deram estimações pontuais, depois, começaram a dar estimações por intervalo, o que os levou a fazer inferências informais, mas muito próximas da realidade.

Nessa mesma perspectiva, Aymerich, Gorgorió e Albarracín (2017) aplicaram uma APM, na qual deviam encontrar a estrutura salarial de certas empresas. A partir disso, emergiram ideias iniciais como o conceito de normalidade e dispersão de dados, favorecendo que os estudantes criassem modelos com diferentes níveis de complexidade para dar respostas às perguntas propostas durante a atividade.

A PMM destaca a construção de sistemas conceituais ou modelos quando os alunos enfrentam situações ou problemas que estimulem o processo de matematização. Desde essa perspectiva, a aprendizagem das matemáticas é o desenvolvimento dos modelos que são refinados continuamente, enquanto o aluno interage com seus colegas e seu professor para resolver uma situação-problema. Os sistemas conceituais conformam-se na mente dos estudantes, e são similares ao que os cientistas cognitivos definem como estruturas cognitivas (LESH; DOERR, 2003), que também estão formadas por meio de representações (Figura 1). Geralmente, o pensamento matemático pode ser expressado em sistemas de notação simbólica estrita, mas, também tendem a envolver a linguagem falada, diagramas, metáforas, modelos concretos e misturas complexas deles (LESH; DOERR, 2003).

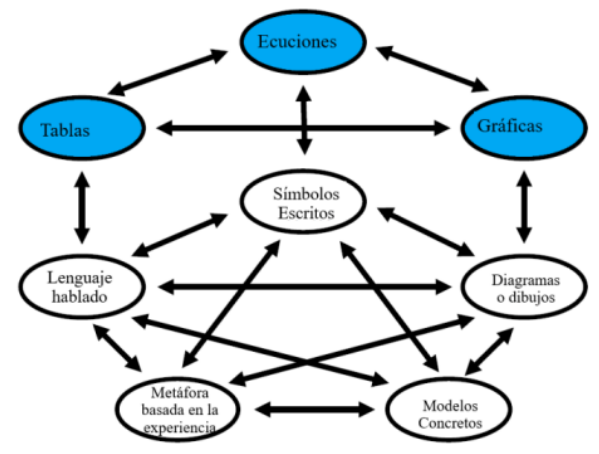

Figura 1 - Meios de representação Fonte: Lesh; Doerr (2003, p. 12) 
De acordo com Lesh e Doerr (2003), os sistemas conceituais que são mais eficazes e úteis raras vezes funcionam em situações complexas, a menos que sejam expressados usando a linguagem falada, símbolos escritos, modelos concretos, diagramas ou imagens, programas de computador, metáforas baseadas na experiência ou outros meios de representação.

A PMM centra-se em que o estudante construa e desenvolva formas de pensamento flexíveis que permitam resolver situações-problemas (LESH; DOERR, 2003; LESH; ENGLISH, 2005; LESH; SRIRAMAN, 2015). Nessa perspectiva, a motivação joga um papel muito importante, pois quando os alunos enfrentam certa situação-problema de seu interesse, são capazes de apropriar-se delas; o que os leva a uma interpretação que gera soluções representadas em termos matemáticos (LEHRER; SCHAUBLE, 2000; LESH; ENGLISH, 2005).

A PMM propõe a implementação de APMs para gerar diversas soluções nas quais os estudantes não apenas traçam respostas as questões propostas, mas, também constroem ferramentas conceituais que podem ser manipuladas, comunicadas e reutilizadas em outras situações (LESH, 2010); de maneira que sejam estendidas até chegar a um modelo generalizável (TRIGUEROS, 2009). Desde a PMM, as APMs são um meio para incitar a criação e desenvolvimento de sistemas conceituais que permitem aos estudantes explicar uma situação proporcionada durante a atividade. A informação nem sempre se apresenta de forma matematizada, e a solução não necessariamente é um procedimento (LESH; YOON, 2004). "A abordagem de uma APM demanda, do estudante, a construção de uma interpretação quantitativa das situações, assim como a realização de vários ciclos de modelação, que requerem diferentes formas de pensamento" (VARGAS-ALEJO; REYES-RODRÍGUEZ; CRISTÓBALESCALANTE, 2018, p. 10).

As APMs produzem algo mais que respostas curtas a perguntas específicas, "envolvem ferramentas conceituais compartilháveis, manipuláveis, modificáveis e reutilizáveis (por exemplo, modelos) para construir, descrever, explicar, manipular, predizer ou controlar sistemas matematicamente significativos" (LESH; DOERR, 2003, p. 3). Estas representam os componentes mais importantes à resposta de um problema. De acordo com Lesh (2010), o processo de aprendizagem das matemáticas implica a vivência de ciclos iterativos de entendimento que o aluno vai modificando, estendendo e refinando conforme vai interagindo com as possíveis soluções de um problema. Durante esses ciclos, os estudantes vão relacionando os dados, os processos e as estratégias para resolver um problema, gerando, em princípio, modelos brutos que se refinam posteriormente (LESH; DOERR, 2003).

Lesh e Doerr (2003) mencionam que no primeiro ciclo de entendimento o aluno tem 
uma interpretação de caráter qualitativo, na qual a situação toma sentido e ocorre o processo de identificação das variáveis implicadas e a relação que existe entre elas, em ausência de medições. O ciclo de entendimento qualitativo utiliza meios representacionais como a metáfora, desenhos e linguagem falada, de maneira que a relação entre variáveis é expressada com termos que descrevem seu comportamento (VARGAS; REYES; CRISTÓBAL, 2016).

Vargas, Reyes e Cristóbal (2016) caracterizaram o segundo ciclo de entendimento como aquele que o aluno dá uma interpretação numérica às variáveis que previamente identificou, e utiliza meios de representação mais complexos que o anterior como tabelas, equações ou gráficos. Trata-se do ciclo de entendimento quantitativo, uma vez que o aluno pode determinar numericamente o que significam as expressões utilizadas no ciclo anterior; ou seja, sistemas de medição para determinar quão menor ou maior, próximo ou distante é ou está um objeto (LESH; DOERR, 2003). Avina, Vargas, Alvarado e Escalante (2019, p. 68) mencionam que “é possível que os alunos exibam descrições qualitativas e quantitativas durante o segundo ciclo de entendimento, mas as variáveis e suas relações utilizam meios representacionais de tabelas e gráficos". Os ciclos de entendimento qualitativo e quantitativo, descritos neste parágrafo e no anterior, foram utilizados como base para a análise dos resultados do estudo.

\section{Metodologia}

Entendido que o resultado da aprendizagem da matemática é o processo, e não o produto final de algum problema, o objetivo deste trabalho é analisar e descrever os ciclos progressivos de entendimento que um grupo de alunos exibiu ao realizar uma APM. Esta investigação teve um enfoque qualitativo com um desenho fenomenológico. Essa abordagem tem o propósito de explorar, descrever e compreender as experiências das pessoas com relação a um fenômeno, e descobrir quais elementos são comuns entre elas (HERNÁNDEZ; FERNÁNDEZ; BAPTISTA, 2014).

Dessa maneira, o fenômeno consistiu na aplicação de uma APM, em dois momentos, e a partir dos dados obtidos, foi realizada a análise, a descrição e a comparação das experiências geradas, por parte dos estudantes, ao construir modelos matemáticos. Foram utilizadas categorias de análise (ciclos de entendimento) para descrever os tipos de variáveis e suas relações, assim como os meios representacionais utilizados pelos estudantes para expressar-se. A análise foi realizada mediante a triangulação temporal dos dados obtidos nas cartas, áudios de gravações das implementações da APM, das anotações na caderneta da professora e dos discursos presentes na expressão externa dos modelos (cartas aos juízes). 
O grupo de enfoque foi integrado por trinta estudantes mexicanos de engenharia industrial, que cursavam a disciplina DE. A APM utilizada foi uma adaptação à publicada por Lesh (2010), denominada Aviões de Papel (Figura 2). A situação proposta aos estudantes foi a necessidade de sugerir, mediante uma carta a um grupo de juízes, um sistema justo para a avaliação em um concurso de aviões de papel. A implementação foi realizada em dois momentos: ao início, para gerar os primeiros sistemas conceituais e para que emergissem ideias iniciais relacionadas com conceitos como experimento, variáveis, réplica, bloqueio, fatores, processo, unidade experimental, matriz de desenho, análise, análise de variância, provas de hipóteses, entre outros, e ao final, para avaliar o refinamento dos sistemas conceituais.

A primeira implementação da APM começou com a leitura da notícia do jornal e as perguntas iniciais. Foram formadas dez equipes no total, às quais foi entregue uma notícia (Figura 2) que descreve as regras de um concurso de aviões que seria realizado em sua universidade, o Centro Universitário de Ciências Exatas e Engenharia (CUCEI em espanhol). Depois, os estudantes responderam umas perguntas de reflexão para assegurar que realmente tinham entendido a notícia. Deviam escrever uma carta aos juízes do concurso para criar um sistema de avaliação justo. A pergunta central foi: Qual é um sistema de avaliação justo para um concurso de aviões de papel quando se busca aquele que é o mais preciso e o melhor voador? Deveriam tomar em consideração duas categorias para a avaliação.

Ao término da redação das cartas, cada equipe leu a sua, de tal maneira que, os pontos positivos e as melhoras de cada modelo foram comentados entre todo o grupo. Essa foi a primeira sessão com o grupo de enfoque. Depois, os conteúdos foram estudados durante quinze sessões (duas horas cada uma). A disciplina foi conduzida ao longo do semestre pela professora, mediante o método expositivo para ensinar os temas. Nesse período, não foi utilizada nenhuma APM, apenas foram resolvidos exercícios e problemas relacionados aos conceitos. 


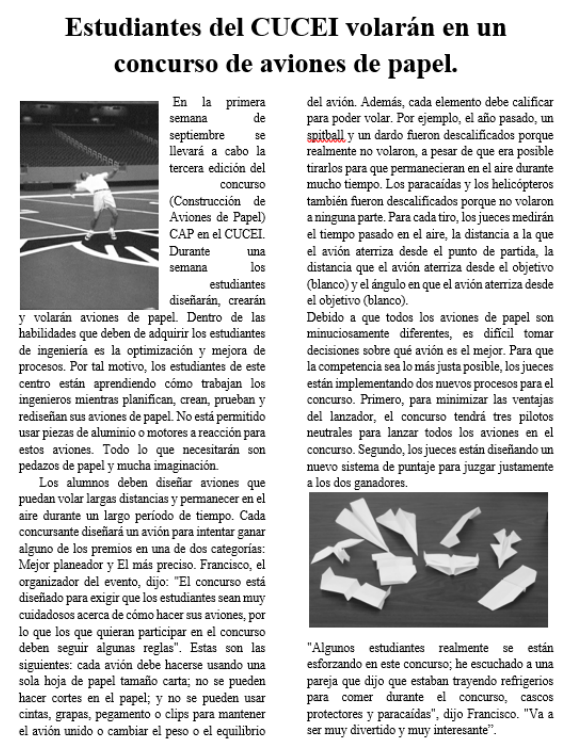

Figura 2 - Notícia do jornal dos aviões de papel Fonte: Lesh (2010)

Ao concluir a disciplina DE, foi implementada novamente a mesma APM, mas com um nível de dificuldade maior, na qual, além da notícia, se incluía uma matriz de desenho (Figura 3) com os dados de uma edição prévia do concurso. Isto supôs um maior nível de complexidade, devido a que a apresentação dos dados demandava que conhecessem quais tipos de variáveis e de dados se coletavam, e davam indícios a que deveriam utilizar estratégias estatísticas mais sofisticadas. De igual maneira, foi pedido que escrevessem uma carta na qual propusessem aos juízes um sistema de avaliação justo para as duas categorias do concurso. Além disso, foi solicitado que, ao final, executassem sua proposta com os dados proporcionados. Uma vez terminada, cada equipe apresentou sua carta, na qual defendiam a pertinência dos desenhos de experimentos utilizados, e concluíram qual foi o mais adequado para resolver a situaçãoproblema.

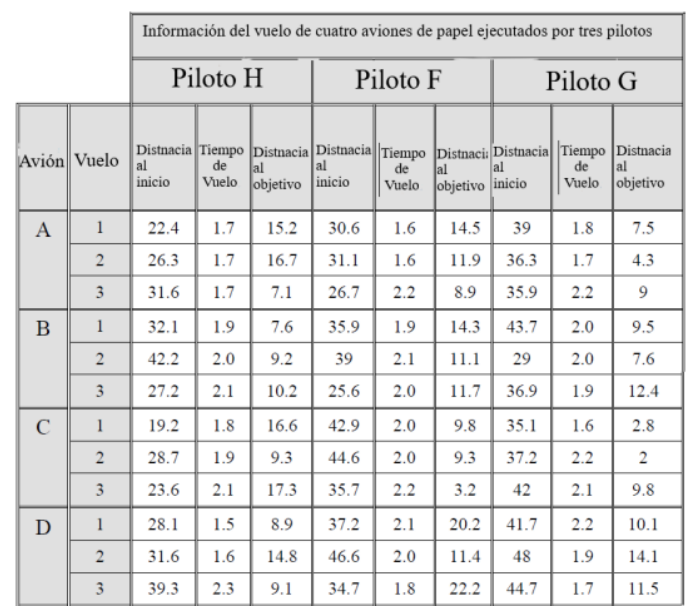

Figura 3 - Matriz de dados com informação do voo de quatro aviões de papel Fonte: Lesh (2010) 


\section{Resultados e análises}

Partindo de que, desde a PMM, o produto da aprendizagem é o processo, e não os modelos finais, neste trabalho foi analisada a evolução de sistemas conceituais que foram modificados, estendidos e refinados a partir de ciclos progressivos de entendimento qualitativos e quantitativos. A análise foi realizada mediante a triangulação temporal dos dados obtidos nas cartas, os áudios gravados em duas sessões e as anotações na caderneta da professora. Graças a isso, foi possível identificar certa fluidez no uso de meios representacionais no momento de construir os modelos, e gerar as categorias que classificaram o processo de aprendizagem.

\subsection{Ciclo de entendimento qualitativo}

No momento de construção dos primeiros modelos (cartas para os juízes), os estudantes identificaram quais variáveis descreveriam o melhor voador e o mais preciso. Iniciaram compartindo suas experiências pessoais na construção e lançamento de aviões de papel; começaram a encontrar coincidências entre seus argumentos, e mencionavam que o melhor voador seria o que chegasse mais longe; outros diziam que seria o que durasse mais tempo voando; outros diziam que o mais preciso seria o que voasse mais direitinho.

Quando começaram a identificar as variáveis para resolver o problema, utilizavam meios representacionais de metáfora, contavam suas experiências com aviões de papel e faziam referência às condições nas que seria realizado o concurso. Nesse ciclo, os primeiros modelos que representavam a solução à situação foram obtidos. Estes eram difusos e pouco estáveis, mas continham características básicas e relevantes que seriam integradas nos próximos modelos alterados pela iteração e interação dos estudantes com o entorno (LESH, 2006). Alguns dos modelos somente chegaram a este ciclo de entendimento. É o caso da equipe 6 , que pode ser visto no Quadro 1. No modelo, apesar de apresentarem variáveis como tempo e distância, os integrantes da equipe 6 não estabeleceram um sistema de medição e de coleta de dados. É relevante mencionar que eles se expressaram mediante uma linguagem falada, e, ainda que não apresentado na carta, essa equipe utilizou desenhos para descrever a trajetória (Figura 4).

Equipe 6: Tudo isto assumindo que os lançadores tenham a mesmo porte e estatura, além de uma base que aplique a proposta anterior e que o lugar em que sería realizado concurso seja um lugar fechado onde não haja influência do vento (Transcrição do modelo inicial, equipe 6 , 2018, p. 18-22). 


\begin{tabular}{|c|c|c|}
\hline 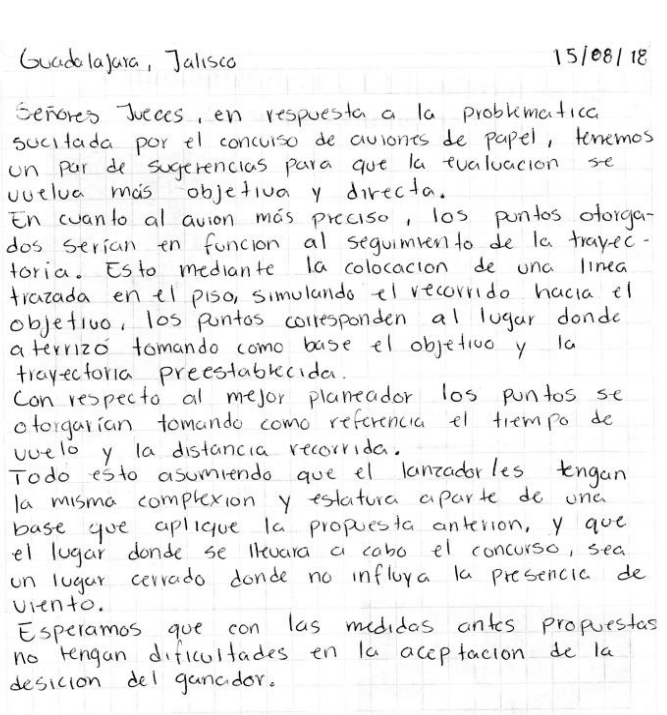 & $\begin{array}{l}10 \\
11 \\
12 \\
13\end{array}$ & $\begin{array}{l}\text { Guadalajara, Jalisco. } \\
\text { Señores jueces, en respuesta a la problemática suscitada por el } \\
\text { concurso de aviones de papel, tenemos un par de sugerencias } \\
\text { para que la evaluación se vuelva más objetiva y directa. } \\
\text { En cuanto al avión más preciso, los puntos otorgados serían en } \\
\text { función al seguimiento de la trayectoria. Esto mediante la } \\
\text { colocación de una línea trazada en el piso, simulando el } \\
\text { recorrido hacia el objetivo, los puntos corresponden al lugar } \\
\text { donde aterrizo tomando como base el objetivo y la trayectoria } \\
\text { preestablecida. } \\
\text { Con respecto al mejor planeador los puntos se otorgarán } \\
\text { tomando como referencia el tiempo de vuelo y la distancia } \\
\text { recorrida. } \\
\text { Todo esto asumiendo que los lanzadores tengan la misma } \\
\text { complexión y estatura aparte de una base que aplique la } \\
\text { propuesta anterior y que el lugar donde se llevara a cabo el } \\
\text { concurso, sea un lugar cerrado donde no influya la presencia de } \\
\text { viento. } \\
\text { Esperamos que con las medidas antes propuestas no tengan } \\
\text { dificultades en la aceptación de la decisión del ganador. } \\
\text { Equipo } 6 .\end{array}$ \\
\hline
\end{tabular}

Quadro 1 - Modelo inicial da Equipe 6: Eq6_1 Fonte: elaborado pela equipe 6

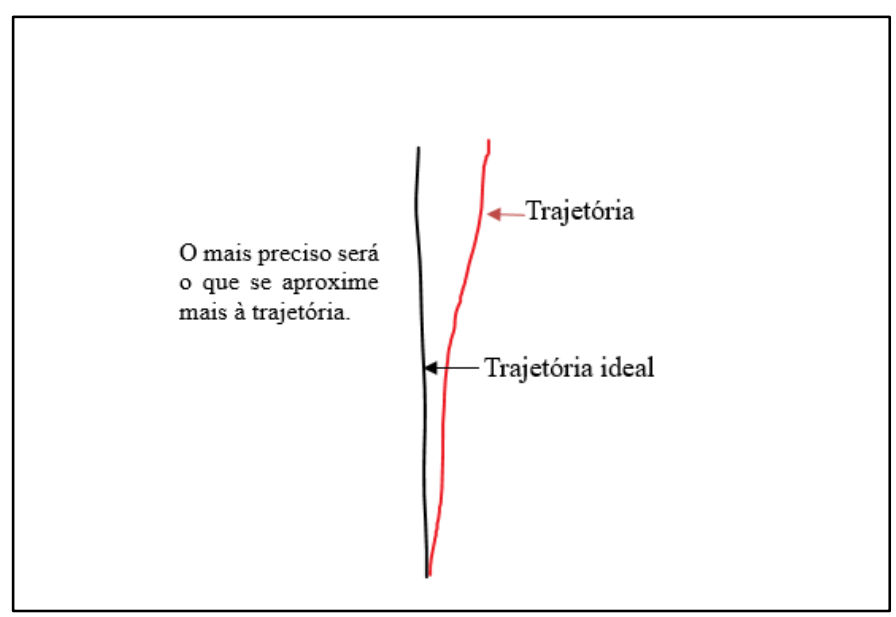

Figura 4 - Desenho que ilustra como determinar o avião mais preciso. Fonte: elaborado pelo autor

Outro exemplo é o modelo 1 da Equipe 9 (Quadro 2), os estudantes utilizaram a linguagem falada e um desenho para expressar suas ideias. Propuseram, para a categoria do melhor voador uma variável qualitativa, o avião que chegue mais longe (Eq9 _1, 2018, p. 10), mas não determinaram um sistema de pontuação. Por outro lado, para a categoria de maior precisão, estabeleceram um sistema de medição com apenas três valores categóricos $(1,5,10)$, mas não ficou claro como fariam a pontuação, somente descreveram que

Equipe 9: o ganhador será o avião que faça mais pontos por aproximar-se dos alvos que serão colocados a 10 metros de distância...(Transcrição do modelo inicial, equipe 9, 2018, p. 15-16). 


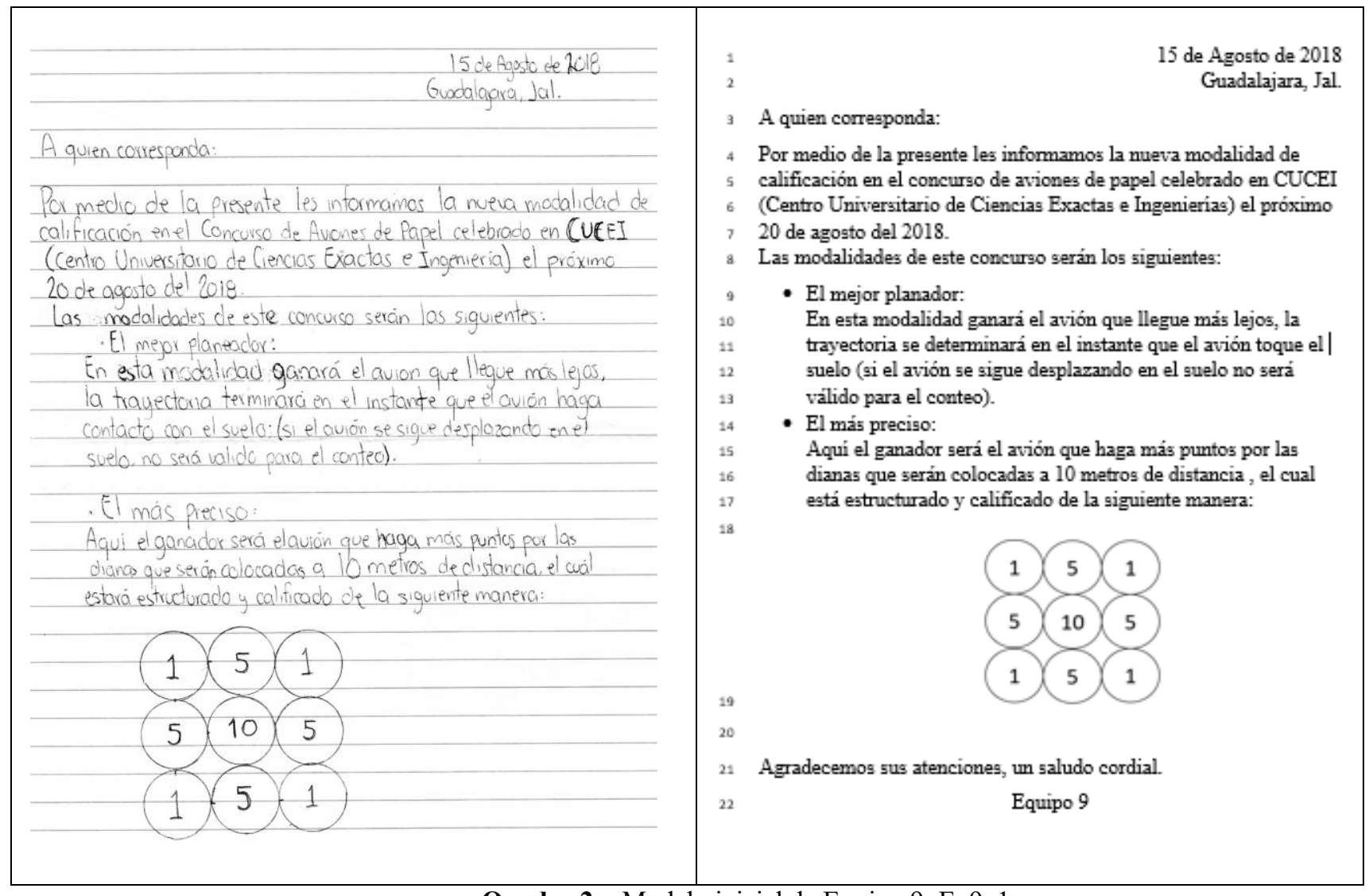

Quadro 2 - Modelo inicial da Equipo 9: Eq9_1

Fonte: elaborado pela equipe 9

Ao analisar as cartas, os áudios e as anotações da professora, foi possível identificar que os estudantes utilizaram, com certa naturalidade, meios representacionais de metáforas, baseados em experiências prévias; linguagem falada, com a qual definiram as condições do entorno e as características do concurso; diagramas ou desenhos, para expressar e ilustrar a situação-problema. As variáveis e relações que utilizaram careciam de informação numérica ou de um sistema de quantificação. No entanto, a identificação dessas variáveis os levou a questionar acerca de como iriam determinar qual seria o avião que chegaria mais longe. Ao responder, algumas equipes $(3,4,5,6,8$ e 10) alcançaram o seguinte ciclo de entendimento.

\subsection{Ciclo de entendimento quantitativo}

Durante a construção dos modelos, alguns alunos começaram a estabelecer variáveis quantitativas associadas à o que chegue mais longe com o que tenha percorrido maior distância desde o início; a variável durava mais voando com o de maior tempo de voo; finalmente, o que voe mais direitinho com o de menor distância a um alvo dado. Depois, foram questionados: como medir? Ao que responderam que tinham que estabelecer um sistema de medição e pontuação. Dessa maneira, foi identificado que os alunos envolviam informação numérica, o 
que implica em haver passado ao ciclo de entendimento quantitativo.

É possível observar no modelo inicial da equipe 3 (Quadro 3) que as variáveis de comparação entre os aviões são de tipo quantitativo, pois propuseram um sistema numérico para a medição das variáveis. Ao início da APM contavam suas experiências ao fazer aviões de papel, quer dizer, expressavam-se mediante metáforas; posteriormente, ao refinar seu modelo, começavam a utilizar linguagem falada para indicar operações matemáticas: será realizada uma segunda somatória e calculada a média... (Eq3_1, 2018, p. 9-10). Também foi possível identificar que os conceitos que emergiram nesse modelo foram: réplica, pois mencionam que, será realizada uma série de tiros a distância com cada um dos aviões (Eq3_1, 2018, p. 9-10); fatores controláveis, sugerem que, É recomendável que as provas sejam realizadas em um lugar fechado... (Eq3_1, 2018, p. 21-23); método de coleta de dados e estimador da média, para o que propõem: o ganhador será o avião que faça mais pontos pelos alvos que serão colocados a 10 metros de distância... (Eq3_1, 2018, p. 15-16).

\begin{tabular}{|c|c|}
\hline 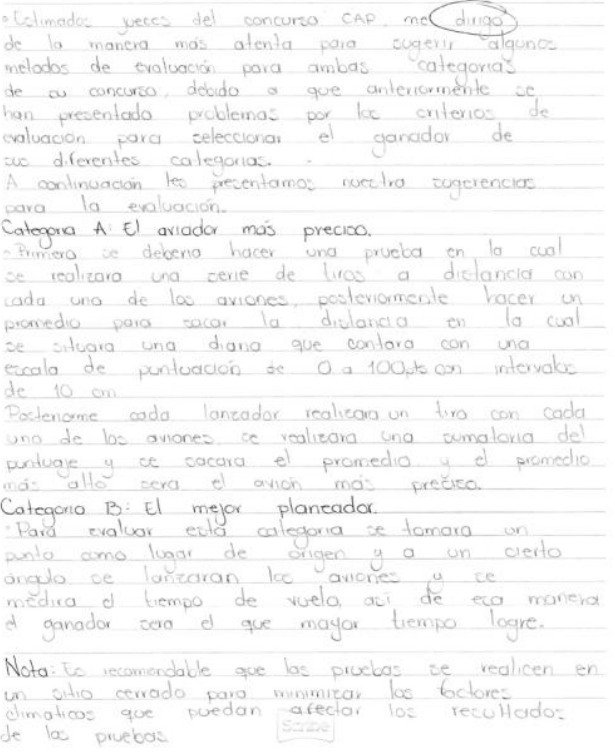 & $\begin{array}{ll}2 & \text { Estimados jueces del CAP, me dirijo a ustedes de la manera más } \\
3 & \text { atenta para sugerir algunos métodos de evaluación para ambas } \\
4 & \text { categorías de su concurso, debido a que anteriormente se han } \\
5 & \text { presentado problemas por los criterios de evaluación para } \\
6 & \text { seleccionar el ganador de sus diferentes categorías. } \\
7 & \text { A continuación presentamos nuestras sugerencias para la evaluación. } \\
8 & \text { Categoría A: El aviador más preciso. } \\
9 & \text { Primero se debería hacer una prueba en la cual se realizara una serie } \\
10 & \text { de tiros a distancia con cada uno de los aviones, posteriormente } \\
11 & \text { hacer un promedio para sacar la distancia en la cual se situara una } \\
12 & \text { diana que contará con una escala de puntuación de 0 a 10 puntos con } \\
13 & \text { intervalos de 10 centímetros. } \\
14 & \text { Posteriormente cada lanzador realizará un tiro con cada uno de los } \\
15 & \text { aviones, se realizará una segunda sumatoria del puntaje y se sacará } \\
16 & \text { promedio y el promedio más alto será el avión más preciso. } \\
17 & \text { Categoría B: El mejor planeador. } \\
18 & \text { Para evaluar esta categoría se tomara un unto como lugar de origen y } \\
19 & \text { a un cierto ángulo se lanzaran los aviones y se medirá el tiempo de } \\
20 & \text { vuelo, así de esa manera el ganador será el que mayor tiempo logre. } \\
21 & \text { Nota: Es recomendable que las pruebas se realicen en un sitio } \\
22 & \text { cerrado para minimizar los factores climáticos que puedan afectar } \\
23 & \text { los resultados de las pruebas. } \\
24 & \text { Quedamos a su disposición y esperamos que nuestras propuestas } \\
25 & \text { sean de su grado. Gracias. } \\
26 & \text { Equipo } 3 .\end{array}$ \\
\hline
\end{tabular}

Quadro 3 - Modelo inicial da Equipe 3: Eq3_1

Fonte: elaborado pela equipe 3

O modelo inicial da equipe 7, apresentado no Quadro 4, propõe um sistema de medição complexo mediante a fórmula de altura máxima, expressado mediante a linguagem falada e equações: propomos adicionar a seguinte fórmula para realizar os cálculos, Altura máximo (Eq7_1, 2018, p. 9-10). No entanto, não mencionam especificamente um sistema de pontuação para determinar ao ganhador. Esse modelo foi criticado por não ser viável; as outras equipes comentavam que não seria simples obter os dados como a velocidade e o ângulo. Para a categoria de maior precisão, sugeriram a fórmula de ângulo de impacto para calcular o anterior mencionado, propomos a seguinte fórmula: Angulo de Impacto (Eq7_1, 2018, p. 17-18). 


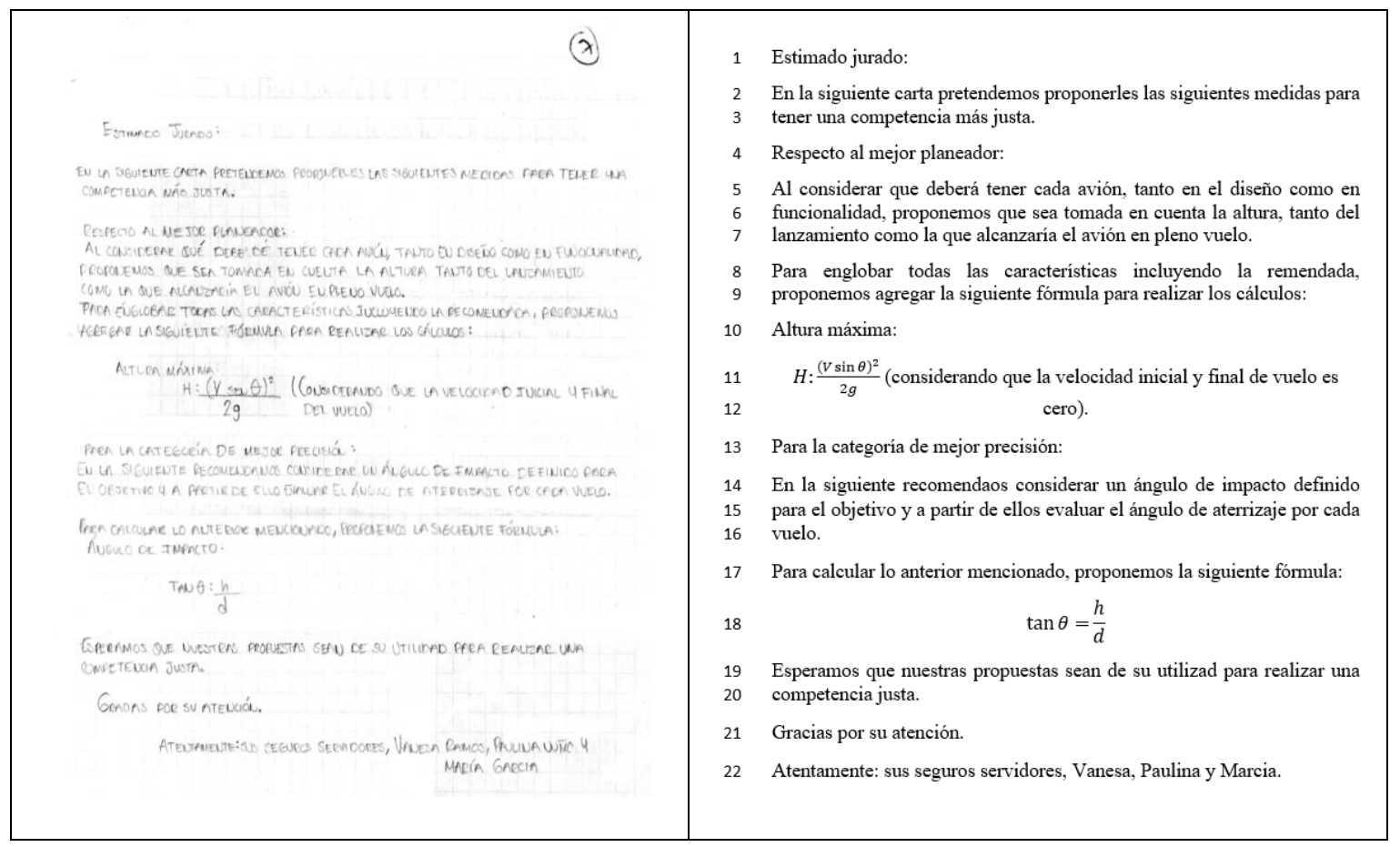

Quadro 4 - Modelo inicial da Equipe 7: Eq7_1 e sua transcrição Fonte: elaborado pela equipe 7

Com base na análise dos dados provenientes das diferentes fontes, foi possível identificar que essas equipes de estudantes utilizavam meios representacionais mais sofisticados, que não se reduziam a descrições qualitativas (como as mostradas na seção 4.1), tais como equações, linguagem falada, metáforas e símbolos escritos, o que significa que seus sistemas anteriores foram modificados e estendidos.

Os estudantes que exibiram o ciclo quantitativo deveriam ter passado, primeiramente, pelo qualitativo, pois esses modelos contêm elementos do ciclo anterior. Apesar disso, cada modelo carece de certos componentes, como precisão para coleta de dados, sistema específico de pontuação etc. Por outro lado, emergiram conceitos básicos teóricos de um desenho de experimentos como variáveis dependentes e independentes, réplica, aleatorização, experimento, bloqueio, fatores, processo, unidade experimental, matriz de desenho, análise, análise de variância, provas de hipótese, entre outros.

No seguinte ciclo foi analisada a evolução que os estudantes tiveram durante a disciplina DE. Pois esses primeiros modelos (descritos nas sessões 4.1 e 4.2) foram, como menciona Lesh e Doerr (2003), brutos e instáveis, mas, conforme passaram as 15 sessões da disciplina, foram evoluídos e refinados. 


\subsection{Ciclo de refinamento}

Os modelos caracterizados nesse ciclo foram analisados a partir dos dados coletados da segunda implementação da APM, uma vez que os temas da disciplina DE foram estudados. Cabe mencionar que, a partir das gravações dessa segunda implementação foi possível identificar que os estudantes exibiram, novamente, os ciclos de entendimento qualitativo e quantitativo (similares aos descritos nas sessões 4.1 e 4.2), porém de maneira mais rápida, porque, em seguida, fizeram associações quantitativas para as variáveis. Esses novos modelos contêm características dos anteriores, conseguiram resgatar que para as categorias era necessário definir duas variáveis independentes entre si, pelo que poderiam ser dois experimentos diferentes e independentes, ainda no mesmo lançamento, e estabeleceram critérios para o controle de fatores como as condições do ambiente e as réplicas nos lançamentos.

No segundo modelo apresentado pela equipe 9 (Quadro 5), os estudantes optaram por um sistema de coleta simples, mas muito eficiente. Neste, as variáveis foram quantitativamente definidas com sistemas de medição e pontuação. Utilizaram meios representacionais da linguagem falada e tabelas, pois sugeriram o uso de uma matriz de desenho para a coleta de dados (Eq9_2, 2018, p. 25 e 31); gráficos LSD (Eq9_2, 2018, p. 33); e equações, quando propõem que, a partir da informação, é viável gerar uma nova variável chamada velocidade, determinada pela divisão da distância e o tempo de voo (Eq9_2, 2018, p. 21-24). Além disto, recuperaram elementos do modelo anterior, como a réplica dos lançamentos (Eq9_2, 2018, p.10-11). Para a análise dos dados propuseram o modelo mais complexo estudado em classe, ANOVA de dois fatores, Depois será resolvida uma ANOVA de dois fatores (Eq9_2, 2018, p. 28). Isso indica que seus modelos iniciais foram refinados. 


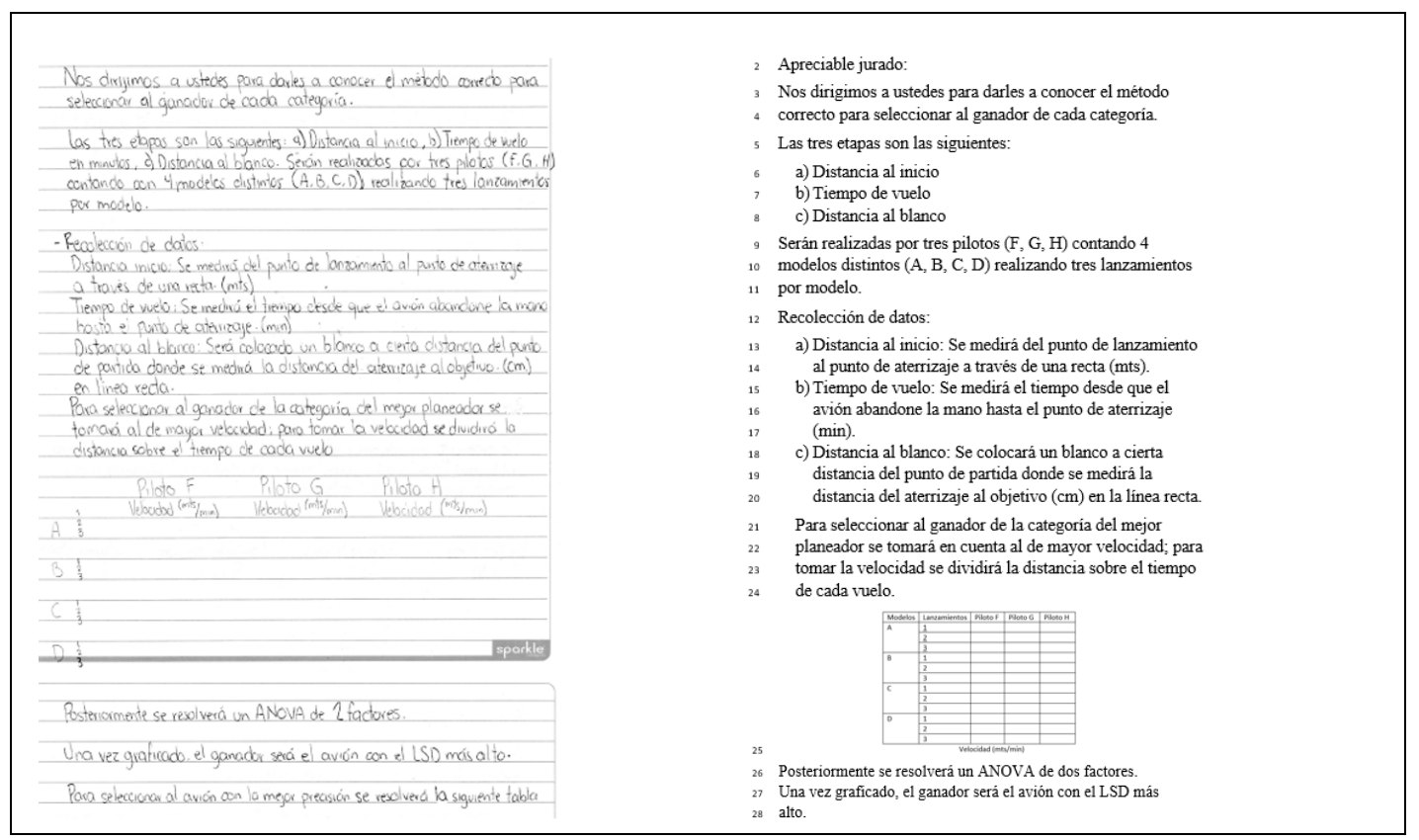

Quadro 5 - Modelo refinado da Equipe 9: Eq9_2 e sua transcrição Fonte: elaborado pela equipe 9

Em sua solução ao problema (Figura 5), a equipe manifestou domínio de técnicas estatísticas e fez uso de três meios representacionais para resolvê-lo: numérico, ao calcular o estatístico $\mathrm{F}$ e o intervalo de confiança para $\mu$; equação; e gráfica, com os que tomam uma decisão, o ganhador é o avião D, posto que tem o lugar mais alto no LSD (Eq9_2, 2018).

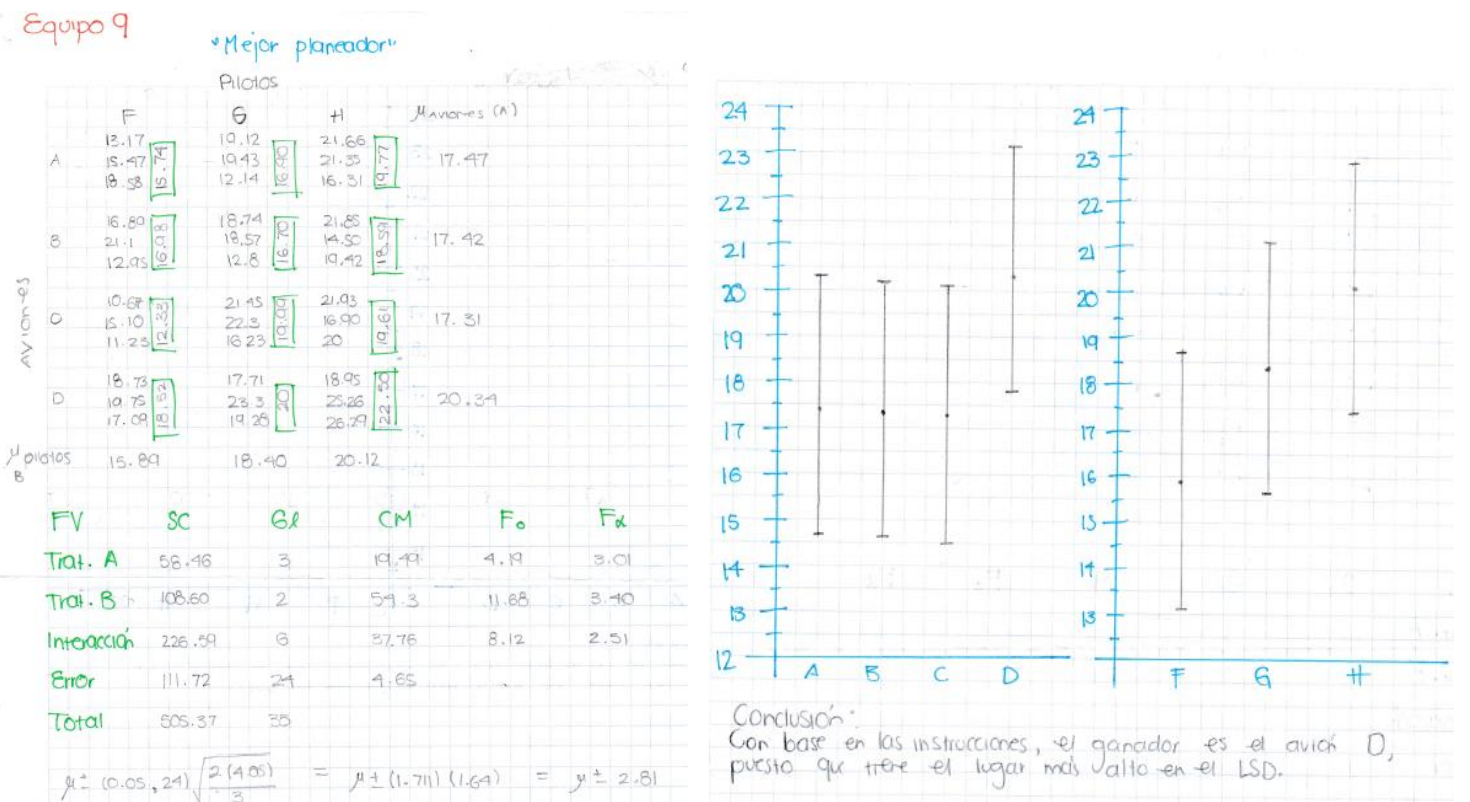

Figura 5 - Solução do problema da equipe 9: Eq9_3

Fonte: elaborado pela equipe 9

No modelo exposto no Quadro 6, a equipe 4 optou pelo desenho de ANOVA de dois fatores. A partir disso, foi evidente que houve uma evolução considerável dos sistemas conceituais, pois a equipe retomou aspectos que foram recorrentes na implementação anterior, 
mas de maneira melhorada. Essa equipe utilizou linguagem falada formal como a realização do experimento será feita a 95\% de confiabilidade... a decisão será tomada ao aceitar ou rejeitar dita hipótese (Eq4_2, 2018, p. 6-31). Essa descrição permite observar o nível de apropriação de conceitos teóricos pelos estudantes. Propuseram um desenho sofisticado de ANOVA de dois fatores, esse método não é o mais adequado, pois envolve os pilotos, e é considerado o efeito de interação entre o modelo e o piloto; no entanto, as variáveis estão claramente definidas, quantitativamente falando, e especificam como serão medidas.

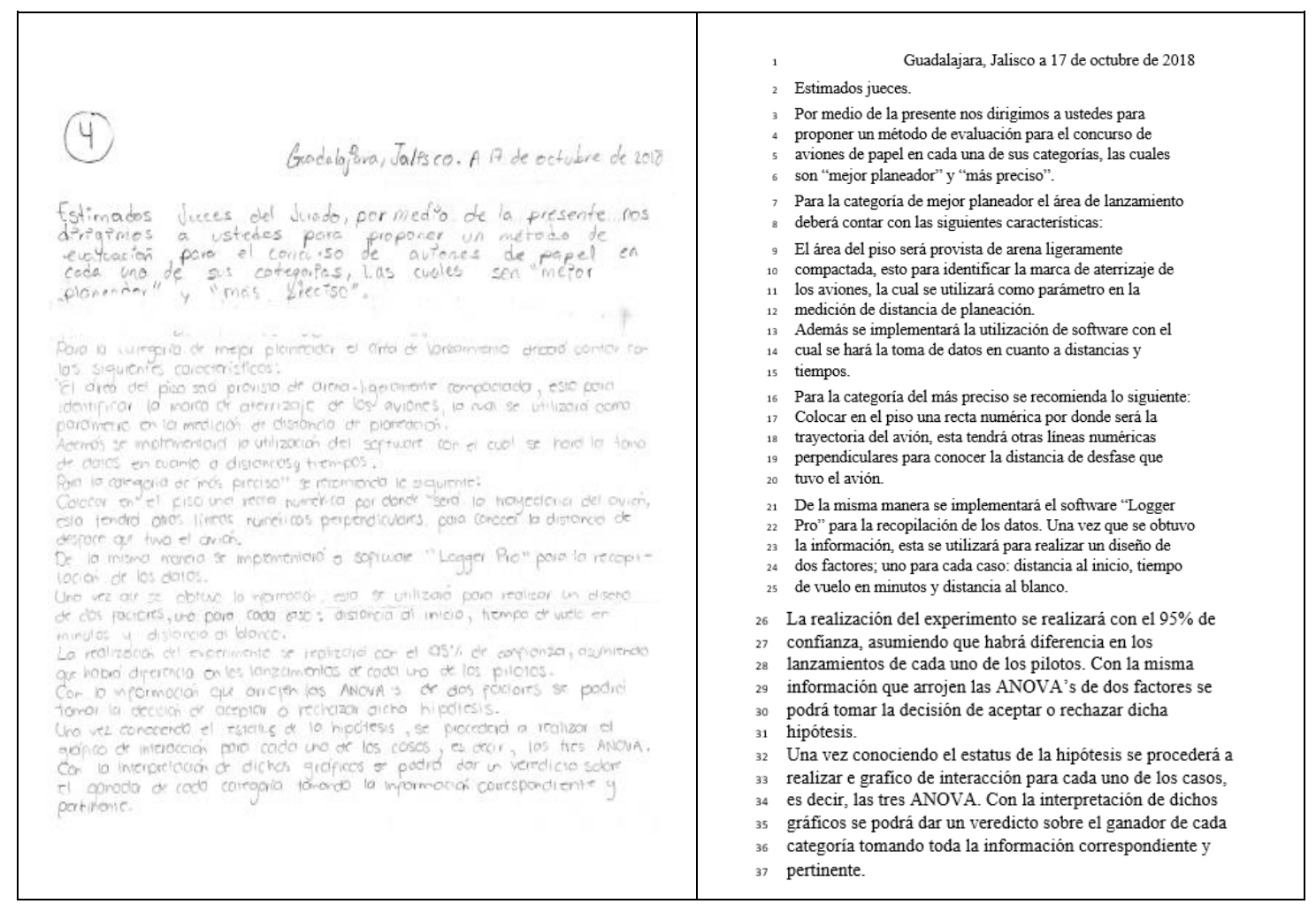

Quadro 6 - Carta aos juízes da Equipe 4: Eq4_2 e sua transcrição Fonte: elaborado pela equipe 4

A Figura 6 mostra a solução do problema da equipe 4, a execução das técnicas estatísticas é correta. Também, é possível perceber que utilizam meios representacionais tabulares para organizar os dados e auxiliar com os cálculos; numéricos, para estimar o estatístico F; e gráficos de interação, para determinar, visualmente, a representação das variáveis de: distância ao início, distância do objetivo e tempo de voo. 

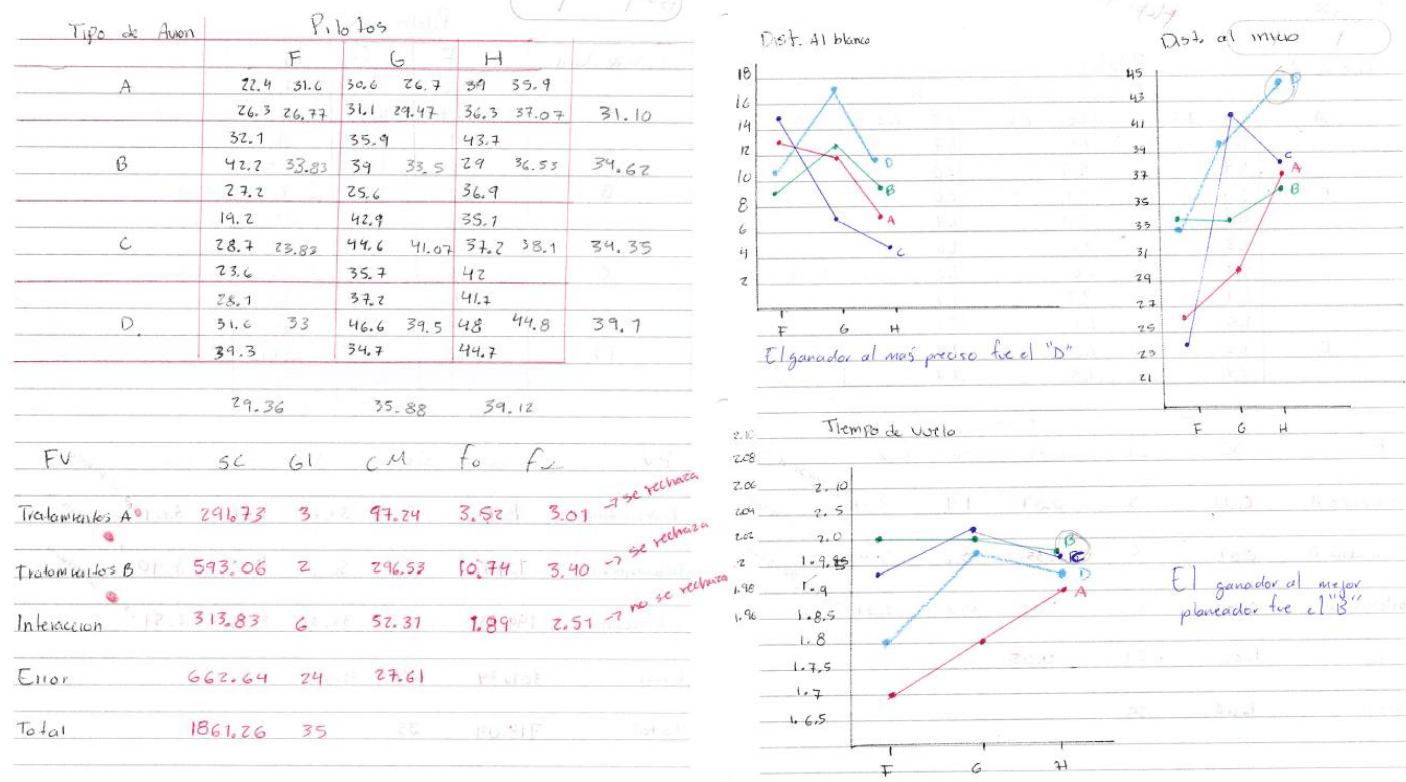

Figura 6 - Solução do problema da equipe 4: Eq4_3

Fonte: elaborado pela equipe 4

O Quadro 7 apresenta o segundo modelo da equipe 3. Neste, em comparação ao modelo anterior, há um refinamento em seu sistema conceitual, mas recuperaram elementos como as variáveis controláveis e não controláveis. Descrevem um sistema conceitual completo para as duas categorias, que vai desde o planejamento e as condições do ambiente, até o desenho de avaliação através de uma ANOVA com bloqueio. Utilizam meios representacionais da linguagem falada para fazer referência ao uso de tabelas para organizar os dados (Eq3_2,2018, p. 40 e 44) e operações matemáticas (Eq3_2, 2018, p. 42-43).

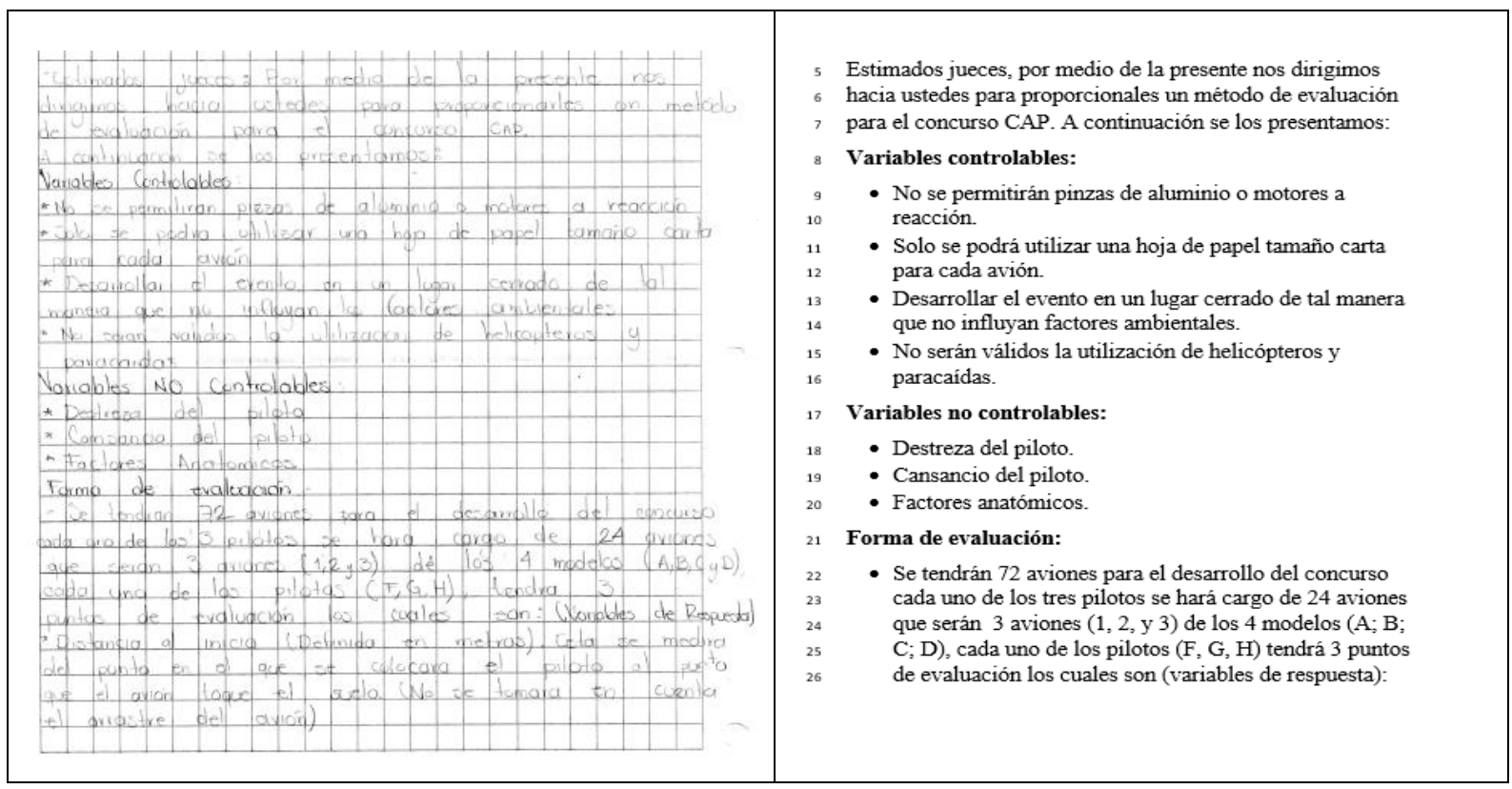




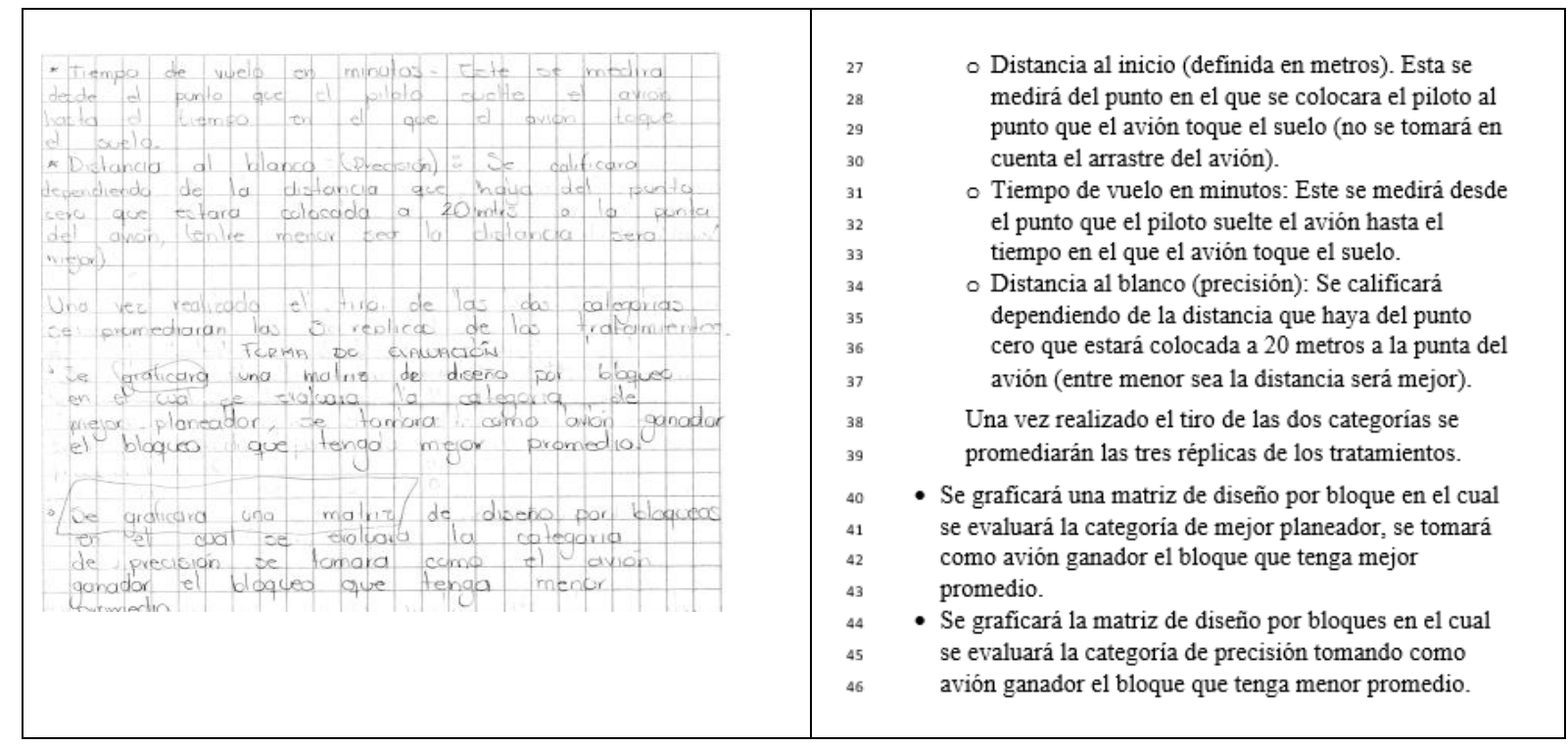

Quadro 7 - Modelo refinado da Equipe 3: Eq3_2

Fonte: elaborado pela equipe 6

Com base nesses modelos e suas análises, é possível afirmar, em termos de Lesh (2010), que os estudantes refinaram e estenderam seus sistemas conceituais iniciais, durante o desenvolvimento de cada uma das aplicações da APM. Na segunda implementação, os estudantes utilizaram sistemas mais complexos e adequados para a solução da situaçãoproblema. Sem dúvida, a primeira implementação ajudou a que os segundos modelos fossem mais completos e precisos.

Além disso, no primeiro ciclo de entendimento (qualitativo) os estudantes utilizavam meios representacionais simples, como o uso de metáforas baseadas em suas próprias experiências (linguagem falada), para expressar as variáveis que interpretavam o problema, e desenhos, para esboçar suas ideias. No segundo ciclo de entendimento, os alunos quantificaram as variáveis e estabeleceram, em alguns casos, métodos sistemáticos de coleta e análise de dados numéricos para a tomada de decisões; também utilizavam meios representacionais da linguagem falada e metáfora. No último ciclo de refinamento, tornou-se evidente que resgataram vários elementos dos ciclos anteriores, como fatores controláveis e réplicas; portanto, há evidências de que esses ciclos são iterativos, nos quais se recupera informação exibida nos modelos anteriores; além disso, os estudantes utilizaram meios mais sofisticados para representar e resolver o problema por meio de tabelas, equações, números e gráficos.

\subsection{Conceitos que emergiram durante a primeira implementação da APM}

Alguns dos propósitos desta investigação foram identificar quais elementos estiveram 
presentes nas estruturas internas dos estudantes no momento de início da disciplina DE, assim como conhecer seus efeitos na aprendizagem dos temas e a forma pela qual emergiram. As ideias e os procedimentos iniciais de estatística, que conformaram os modelos dos estudantes no começo da disciplina, emergiram durante a primeira implementação da APM, mas os estudantes não o fizeram por si mesmos, senão que a professora apoiou mediante perguntas auxiliares para que eles exibissem, de maneira natural.

Essa ação funcionou como estrutura prévia para modificar, ampliar e refinar conceitos e procedimentos. Na Figura 7 são mostrados, em cor negra, os elementos que conformavam o sistema conceitual ensinado, e em cor verde, como foi que emergiram durante a primeira sessão plenária. Durante a disciplina, sempre que os alunos queriam dar um exemplo de algum conceito, lembravam daqueles surgidos durante a APM e, posteriormente, os relacionavam com os novos exercícios ou problemas. Por exemplo, quando definiram os fatores controláveis, recordavam que para o concurso de aviões deveriam manipular as condições ambientais, e que dispunham de apenas três pilotos para fazer os lançamentos; depois os extrapolaram ao exercício ou problema do momento.

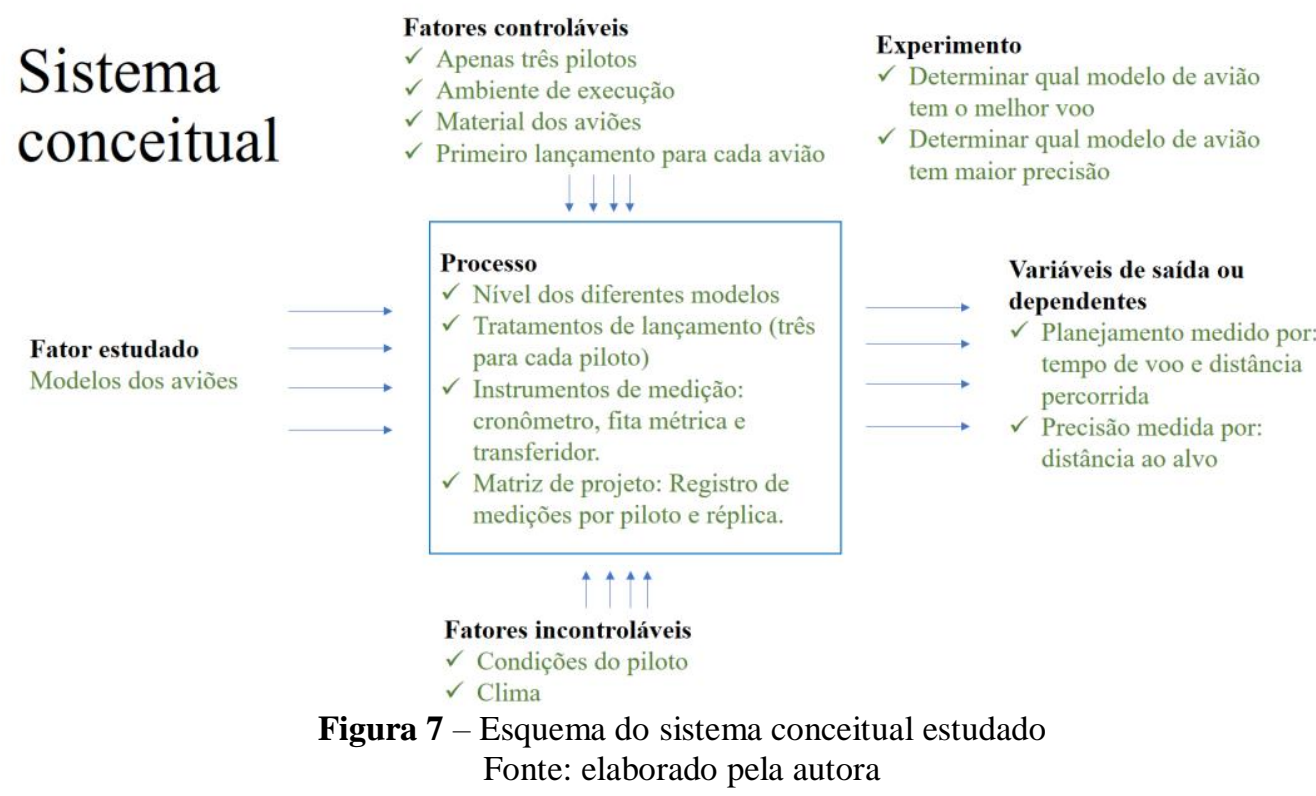

\section{Conclusões}

A partir da análise dos resultados das implementações da APM a um grupo de estudantes, foi possível gerar três categorias que envolvem três ciclos progressivos de entendimento. $\mathrm{O}$ que permite responder à primeira pergunta: como são desenvolvidos os ciclos de entendimento para modelar os desenhos de experimento e provas de hipóteses? De acordo com Lesh e Doerr (2003) e Lesh (2010), os estudantes exibiram modelos que foram evoluindo 
mediante esses ciclos, nos quais os dois primeiros níveis progressivos de entendimento ajustaram-se à caracterização proposta por argas, Reyes e Cristóbal (2016), em qualitativo e quantitativo. No princípio, os modelos eram brutos, careciam de informação precisa e de propriedade para resolver o problema, mas, conforme foi passando o tempo, foram refinados, estendidos e generalizados.

O primeiro ciclo de entendimento, definido como qualitativo, foi caracterizado pelo uso de meios representacionais, principalmente, da linguagem falada, com o que expressaram as condições do entorno e as bases do concurso; de metáforas baseadas na experiência de construção de aviões de papel; diagramas ou desenhos, que ilustraram suas ideias e interpretaram a situação problema. As variáveis utilizadas e suas relações foram de caráter qualitativo, pois careciam de informação numérica ou de um sistema de quantificação.

O segundo ciclo identificado foi o quantitativo. Neste, os estudantes utilizavam meios representacionais que incluíam os anteriores (linguagem falada, metáforas e diagramas), mas adicionaram equações e números. As variáveis utilizadas e suas relações foram de tipo quantitativo, pois estabeleceram tipo de dados numéricos para medi-las. Os estudantes que exibiram o ciclo quantitativo, primeiramente, expuseram o qualitativo, devido a que esses novos modelos continham elementos do ciclo anterior, o que significa que seus sistemas anteriores foram modificados, estendidos e melhorados. O resultado coincide com o de Avina, Vargas, Alvarado e Escalante (2019), quem mencionam que, possivelmente, no segundo ciclo os estudantes exibiram descrições de tipo qualitativas e quantitativas.

No último ciclo de refinamento, é evidente que retomaram vários aspectos dos anteriores, pois há indícios de que esses ciclos são iterativos. Além disso, os estudantes utilizaram meios mais sofisticados para representar e resolver o problema por meio de tabelas, equações, números e gráficos. De acordo com Lesh e Doerr (2003) os sistemas conceituais que são mais eficazes e úteis funcionam em situações complexas, quando se expressam diversos meios de representação. Nesse ciclo, os estudantes desenvolveram conhecimentos e processos estatísticos, que os levaram a tomar decisões mais corretas e fundamentadas.

Os estudantes exibiram sistemas conceituais mais completos e robustos para a solução da situação-problema na segunda implementação da APM, o que foi possível graças a que foram identificados quais conceitos e procedimentos conformavam cada um dos modelos construídos pelos estudantes no começo da disciplina, durante a implementação da primeira APM; conforme passaram as classes, utilizavam uma linguagem mais formal e adequada, o que constituiu modelos mais precisos.

O uso de estratégias inovadoras no ensino da estatística, como a aplicação das APMs, 
estimula a criação de ferramentas poderosas para o desenvolvimento do pensamento analítico e o raciocínio dedutivo dos estudantes, auxiliando na resolução de problemas e tomada de decisões que estão fundamentadas na análise da informação.

\section{Referências}

AVINA, M.; VARGAS, V.; ALVARADO, A.; ESCALANTE, C. Understanding Cycles on College Students on Solving Activity Related with Proportionality. Revista de Investigación Educativa, n. 29, p. 58-86, 2019.

AYMERICH, À.; GORGORIÓ, N.; ALBARRACÍN, L. Modelling with Statistical Data: Characterisation of Student Models. In: STILLMAN, A.; BLUM W.; KAISER G. (Eds.).

Mathematical, Modelling and Applications. Cham: Springer International Publishing AG, 2017. p. $37-48$.

BATANERO, C. Didáctica de la Estadística. Granada: Grupo de Investigación en Educación Estadística, 2001.

DOERR, H. M.; DELMAS, R.; MAKAR, K. A modeling approach to the development of students' informal inferential reasoning. Statistics Education Research Journal, Auckland, v. 16 n. 2, p. 86$115,2017$.

DVIR, M.; BEN-ZVI, D. The role of model comparison in young learners' reasoning with statistical models and modeling. ZDM Mathematics Education, Karlsruhe, v. 50, n. 7, p. 1183-1196, 2018.

GAL, I. Adult's statistical literacy. Meanings, components, responsibilities. International Statistical Review, The Hague, v. 70, n. 1, p. 1-25, 2002.

HERNÁNDEZ, R; FERNÁNDEZ, C.; BAPTISTA M. P. Metodología de la investigación. Cidade do México: McGraw-Hill, 2014.

LEHRER, R.; SCHAUBLE, L. Inventing data structures for representational purposes: Elementary grade students' classification models. Mathematical Thinking and learning, London, n. 2, p. 51-74, 2000 .

LESH, R. Modeling Students Modeling Abilities: The Teaching and Learning of Complex Systems in Education. Journal of the Learning Sciences, London, v. 15, n. 1, p. 45-52, 2006.

LESH, R. Tools, researchable issues and conjectures for investigating what it means to understand statistics (or other topics) meaningfully. Journal of Mathematical Modeling and Application, Blumenau, v. 1, n. 2, p. 16-48, 2010.

LESH, R.; DOERR, H. Foundations of a Models and Modeling Perspective on Mathematics Teaching, Learning, and Problem Solving. In: LESH, R.; DOERR, H. (Eds.). Beyond Constructivism Models and Modeling Perspectives on Mathematics Problem Solving, Learning, and Teaching. Mahwah: Lawrence Erlbaum Associates 2003. p. 3-34.

LESH, R.; HAREL, G. Problem Solving, Modeling, and Local Conceptual Development.

Mathematical Thinking and Learning, London, v. 5, n. 2, 2003.

LESH, R.; YOON, C. Evolving communities of mind -In which development involves several interacting and simultaneously developing strands. Mathematical Thinking and Learning, London, v. 6 , n. 2, p. 205-226, 2004. 
LESH, R.; ENGLISH, L.Trends in the evolution of the Models and Modeling perspectiveson mathematical learning and problem solving. International Journal on Mathematics Education, Karlsruhe, v. 36, n. 7, p. 487-489, 2005.

LESH, R.; SRIRAMAN, B. Mathematics education as design science. Zentralblatt für Didaktik der Mathematik, Karlsruhe, v. 37, n. 6, p. 490-505, 2015.

RODRÍGUEZ-MUÑIZ L.; DIAZ. P. Las investigaciones sobre la estadística y la probabilidad en los libros de texto de Bachillerato. ¿Qué se ha hecho y qué se puede hacer? Avances de Investigación en Educación Matemática, Granada, n.14, 65-81, 2018.

SÁNCHEZ, V. J. Las ideas fundamentales de probabilidad en el razonamiento de estudiantes de bachillerato. Avances de Investigación en Educación Matemática, Granada, n. 11, p. 127- 143, 2017.

TRIGUEROS, M. El uso de la modelación en la enseñanza de las matemáticas. Innovación Educativa, Cidade do México, v. 9, n. 45, p. 75-87, 2009.

VARGAS, V.; REYES, A.; CRISTÓBAL, C. Ciclos de entendimiento de los concpetos de función y variación. Educación Matemática, Cidade do México, v. 28, n. 2, p. 59-83, 2016.

VARGAS-ALEJO, V.; REYES-RODRÍGUEZ, A.; CRISTÓBAL-ESCALANTE, C. La deforestación como consecuencia del incremento de áreas de cultivo: Actividad Provocadora de Modelos. Epsilon, Sevilla, n. 99, p. 7-27, 2018.

ZAPATA-CARDONA, L. Students' construction and use of statistical models: a socio-critical perspective. ZDM Mathematics Education, Karlsruhe, v. 50, n. 7, p. 1213-1222, 2018.

Submetido em 05 de Maio de 2020. Aprovado em 13 de Dezembro de 2020. 